\title{
More than Just a Woman Physicist
}

\section{Approaches that consider the intersection of multiple social and personal identities are urgently needed to understand why women are underrepresented in physics.}

\section{By Lucy Avraamidou}

want to share a story. The story

is not my own but is that of Amina, a "woman in physics."

Amina told me her story a few years ago, during an investigation I conducted into the barriers, difficulties, and conflicts faced by women trying to succeed in physics. The story documents her journey to becoming a physicist, her persistence and failures, and her sense of never really belonging in physics throughout her studies and career.

The story also highlights another important issue: Amina is not just a woman physicist. Amina is also a Muslim, a

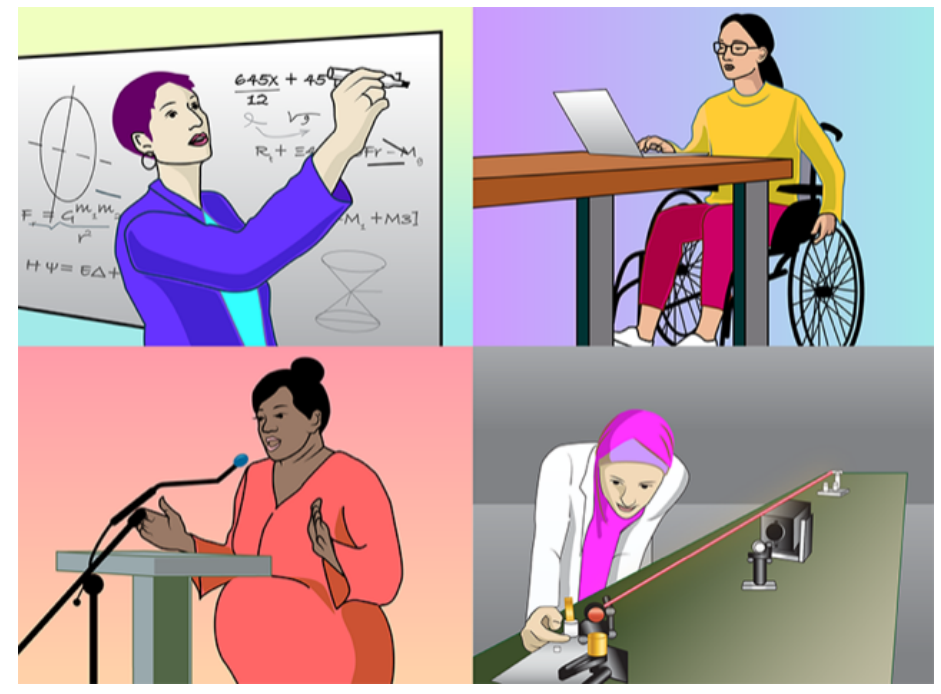

Physics needs diversity policies that account for each person's unique identities and experiences.

Credit: APS/Carin Cain
Kurdish-Turkish migrant to Western Europe, a daughter, a sister, a wife, a mother, and a friend. These many interconnected identities weave together in a unique way to make her who she is. They also position her as an outsider in physics, which has historically been a largely white, male, and atheist field.

The issue of how the overlapping of identities (e.g., gender, class, race) creates privilege, power, marginalization, and exclusion is defined through intersectionality-a framework for understanding the combined effects of intersected identities. Intersectionality often gets swept under the carpet in discussions about increasing the representation of women in physics, which tend to assume that women are a monolith and that they all face the same struggles. But that is not true: Each woman has her own story. And, if we truly want to increase diversity in physics, we need to implement policies that can account for each person's unique identities and experiences and then address the complexity of the set of prejudices that they face.

Amina was born and raised in Turkey, where she studied physics. During her undergraduate studies, she was one of only two female students in the physics classroom. During her studies, she had just one female instructor. In order to enter buildings at the university, Amina had to take off her hijab because of a national law that was in effect at the time. "I had to sacrifice my religious beliefs for physics," she said when I spoke to her. "I felt oppressed as a Muslim woman. Muslim men could enter the university premises without a problem. But as a woman who chose to wear a hijab [...] I felt-and still [feel]-discriminated against." 
Amina completed her master's and Ph.D. physics degrees in the US. During her graduate studies, Amina said that she was frequently confronted with the question: "How come you study physics if you are Muslim? Aren't physicists atheists?" This question reveals a tension between two identities that are often perceived as conflicting: being a physicist and being religious. Another tension is revealed through another question Amina was often asked around the same time: "Why don't you come back to Turkey and have children?" This question embodies cultural expectations of women and ties being a mother to being successful as a woman, regardless of professional achievements.

For Amina, these clashes made her feel as if she was an outsider in every situation, a common feeling for many with marginalized identities. This issue can leave people feeling that they have to erase aspects of who they really are in order to "fit in" in certain places, something that can exacerbate their sense of exclusion and suffering.

To combat this problem, physics needs to adopt critical feminist and intersectional frameworks and methodologies when examining the participation of women. Such an approach will uncover the inequalities experienced by women and will improve hiring and promotion policies as well as aid in the design of more inclusive learning environments. These frameworks do not require women to erase parts of themselves but instead invite them to bring their whole selves to the table. Avoiding that erasure is the goal of inclusivity. An intersectional approach to examining women's participation in physics could also help to better recognize their contributions and add meaning to what it is to become a physicist.

Amina left her career in academia after four years of being a lecturer in Western Europe, ending her physics journey. Did she leave just because she is a woman? No. Did she leave just because she is Muslim? No. She left because her intersectional identities continually positioned her as an outsider in physics. It's only when we realize how the intersection of gender with other marginalized identities causes exclusion that we will be able to address the problem of the underrepresentation of women, and other minorities, in physics.

Lucy Avraamidou: Institute for Science Education and Communication, University of Groningen, Groningen, Netherlands 